DOI 10.37882/2223-2982.2020.06-2.12

\title{
СОДЕРЖАНИЕ ПОНЯТИЯ «ХУДОЖЕСТВЕННАЯ ДЕЯТЕЛЬНОСТЬ» В ТЕОРИИ И ПРАКТИКЕ ОБЩЕГО ОБРАЗОВАНИЯ
}

\section{CONTENT OF THE CONCEPT OF "ARTISTIC ACTIVITY» IN THEORY AND PRACTICE OF GENERAL EDUCATION}

\section{O. Denisenko}

Summary: The relevance of the research is determined by the fact that to date, the theory and practice of General education has not developed a unified approach to determining the content of artistic activity in General education institutions. Based on the study of normative, educational and methodological documentation and the experience of teachers, THE author comes to the conclusion that in the current practice of teaching fine arts, the potential of artistic activity in the formation of a teenager's personality is not fully used.

Keywords: education, artistic activity, student, adolescence, perception.

\author{
Денисенко Олеся Анатольевна \\ Аспирант, ФГБОУ ВО «Башкирский государственный \\ педагогический университет им. М. Акмуллы» (2. Уфа) \\ mak-olesya@yandex.ru
}

Аннотация: Актуальность исследования определяется тем, что до настоящего времени в теории и практике общего образования не выработано единого подхода к определению содержания художественной деятельности в общеобразовательных учреждениях. На основе изучения нормативной, учебнометодической документации и опыта работы педагогов ИЗО автор приходит к выводу, что в сложившейся на сегодняшний день практике преподавания изобразительного искусства потенциал художественной деятельности в формировании личности подростка не используется в полной мере.

Ключевые слова: образование, художественная деятельность, обучающийся, подростковый возраст, восприятие.

\section{Введение}

A ктуальность исследования. Современная социокультурная ситуация делает актуальной задачу школы по формированию общей культуры обучающихся, их духовно-нравственного и личностного развития. Стратегия воспитания в Российской Федерации предполагает развитие форм включения детей в разные виды деятельности, в том числе художественно-эстетическую [25].

Государством подчеркивается значимость художественной деятельности в развитии гармоничной творческой личности, выстроена система нормативно-правового регулирования данного процесса. Анализируя нормативные основы сферы образования, регламентирующие требования по направлению «Искусство», такие, как Федеральный закон от 29 декабря 2012 г. №273-Ф3 «Об образовании в Российской Федерации», федеральный государственный образовательный стандарт основного общего образования можно отметить, что в них предусмотрена практическая художественно-творческая деятельность обучающихся, имеется ссылка на основные виды художественно-творческой деятельности $[7 ; 17 ; 29]$.

В системе образования художественное развитие, эстетическое воспитание и активизация творческих способностей личности детей осуществляется в рамках освоения дисциплин предметной области «Искусство». Для того чтобы педагогическое воздействие в сфере личностного развития ребенка было более эффективным, в школе должна быть создана система художественной деятельности, при этом, каждому педагогу необходимо четкое понимание поставленных задач в области педагогического проектирования художественного воспитания и развития детей.

Системный подход предполагает, что процесс преподавания в школе дисциплин предметной области «Искусство» должен быть сконструирован как система, порождаемая осознанной целью с точно обозначенными необходимыми и достаточными элементами, взаимодействие которых определяет исход процесса [31, с. 11]. В методологическом плане художественная деятельность вычленяется из общей среды, потому что является одним из видов деятельности человека, средством развития определенных способностей, свойств человека.

Необходимо отметить, что проблема изучения функции художественной деятельности в процессе формирования личности и значение художественной деятельности в обучении и развитии обучающихся неоднократно становилась предметом внимания исследователей: в педагогике - Т.Г. Пузыни, И.В. Таньчевой [18; 26], в психологии - В.В. Горевым, В.А. Корнеевой [6; 12], в дополнительном образовании - Т.Ю. Большаковой [4]. В системе общего образования активно используются методы пе- 
дагогики искусства [2].

В учебно-методической литературе, рабочих программах по изобразительному искусству учебный процесс представлен такими основными формами учебной художественной деятельности, как практическое художественное творчество посредством овладения художественными материалами, зрительское восприятие произведений искусства и эстетическое наблюдение за окружающим миром [9, с. 3].

Анализ преподавания дисциплин художественного цикла в общеобразовательных школах свидетельствует о том, что в большинстве случаев педагоги ориентируются на продуктивную практическую художественнотворческую деятельность обучающихся [28], но задачи освоения программ предметной области «Искусство» гораздо шире. Например, основные задачи предмета «Изобразительное искусство» и предметные результаты такие, как формирование опыта смыслового и эмоционально-ценностного восприятия визуального образа реальности и произведений искусства, овладение практическими умениями и навыками в восприятии, анализе и оценке произведений искусства не решаются педагогами на практике $[9$, с. 3; 10, с.13].

Согласно требованиям Федерального государственного образовательного стандарта основного общего образования (5-9 кл.) в учебный план входят обязательные предметные области и учебные предметы: искусство (изобразительное искусство, музыка). Среди условий реализации основной образовательной программы основного общего образования выделено обеспечение возможности формирования у обучающихся опыта самостоятельной художественной деятельности. Однако в изученных нами нормативных документах не дается понятие «художественная деятельность». Между тем понятийный аспект в педагогике имеет особую методологическую значимость. В педагогической практике от точного владения учителем понятийно-категориальным аппаратом зависит успех всего учебно-воспитательного процесса.

Таким образом, актуальность выбранной темы вытекает из педагогической практики и обуславливается проблемой понимания педагогами задач художественного развития обучающихся.

Для реализации поставленной цели необходимо решить ряд задач:

- изучить научно-педагогическую литературу, научные исследования по проблеме понимания художественной деятельности как вида человеческой деятельности;

- рассмотреть процесс обучения предмету «Изобразительное искусство» в школе, выявить осо- бенности;

- сформулировать методические рекомендации для педагогов, преподающих предметы художественно-эстетического цикла.

Для выявления сущности художественной деятельности в системе образования, в статье применяются следующие методы исследования: метод контент-анализа и метод анализа понятийно-терминологической системы. С помощью системного подхода обеспечивается описание процесса художественной деятельности в школе.

\section{Основная часть}

Для решения поставленных задач, прежде всего, необходимо рассмотреть художественную деятельность как вид человеческой деятельности, поскольку художественная деятельность профессионала и художественная деятельность обучающихся в школе имеет сходные основы, хотя эти понятия нельзя рассматривать как тождественные [8, с. 12].

Художественная деятельность как категория анализировалась в эстетической литературе. Имеется детальное исследование философа М.С. Кагана, в котором художественная деятельность рассматривается как информационная система [11, с. 208-239]. В книге ученыхпедагогов А.М. Новикова и Д.А. Новикова «Методология» одна из глав посвящена методологии художественной деятельности [16, с. 374-435].

Так, М.С. Каган подробно рассматривает художественную деятельность, и понимает под ней единую систему, состоящую из трех звеньев, таких, как: творчество художника, продукты творчества или искусства и художественное восприятие [11, с. 216].

М.С. Каган выделяет процесс восприятия искусства как деятельность, как бы повторяющую в обратном порядке структуру творческой деятельности художника [11, с. 229]. То есть, зритель одновременно воспринимает продукт деятельности автора в целом, изучает выразительные средства, детали, испытывает эмоции, и может понять замысел автора и осмыслить содержание произведения искусства. М.С. Каган отмечает синкретизм художественной деятельности (слияние преобразовательной, познавательной, ценностно-ориентационной, коммуникативной деятельностями) и определяет художественную деятельность как прочесс разработки, хранения и передачи определенной конкретной информации [11, с. 216]. Ученый выделяет особенности художественной информации, в которой, в отличие от научной, содержится знание «не об объективный законах реального мира, а о значениях, смыслах, ченностях, которые объект имеет для субъекта, природа - для общества, 
мир - для человека» [11, с. 217, курсив М.К. - О.Д.]. Художественная информация вбирает в себя «субъективное, сочиально-групповое и интимно-личностное отношение к отражаемому» [11, с. 217, курсив М.К. - О.Д.]. При этом художественная информация обладает «двухслойным психологическим строением, имея рациональный и эмоциональный уровни» [11, с. 217, курсив М.К. - О.Д.], т.е. в художественной информации сливаются воедино мысль с чувством, страстью, переживанием.

М.С. Каган отмечает необходимость человечеству художественной информации в такой же мере, как и научной, документальной, идеологической, прогностической. Именно поэтому «исторически сложился особый вид человеческой деятельности, призванный вырабатывать и распространять этот специфический род информации» [11, с. 217].

В свою очередь, А.М. Новиков, Д.А. Новиков рассматривают художественную деятельность как профессиональную, анализируют ее по отношению к художнику, отмечают потребность автора в наличии специфических способностей, таланте и определяют художественную деятельность как самостоятельное эстетическое творчество в области искусства и литературы [16, с. 72].

В педагогических работах художественная деятельность обучающихся рассматривается в одном из своих аспектов: делается акцент на создание нового продукта художественного творчества, и таким образом художественная деятельность рассматривается как творческая. Так, А.Ш. Амирджанова отмечает связь понятия художественная деятельность с творчеством и рассматривает художественную деятельность как особый вид творческой деятельности [1]. Т.Ю. Большакова выявляет сущность интегративной художественной деятельности, и определяет ее как особый тип художественно-образовательной деятельности для подготовки и реализации общего творческого действия [4].

Для решения первой задачи на теоретическом уровне был использован метод анализа понятийно-терминологической системы, который позволил сделать вывод о том, что:

- понятие художественной деятельности как особого вида человеческой деятельности используется в научных исследованиях, научно-педагогической литературе, в которых предлагаются разные трактовки данного понятия. Но содержание художественной деятельности как категории теории образования в изученных нами источниках не представлено.

- М.С. Каган характеризует художественную деятельность как информационную систему, выявляет специфику и необходимость данной информации для человека, определяет структуру и составные системные элементы художественной деятельности - во взаимосвязи и взаимообусловленности. Поэтому определение художественной деятельности М.С. Кагана взято за основу нашего исследования.

Для решения второй задачи по получению данных об особенностях преподавания «Изобразительного искусства» в школе необходимо рассмотреть основные требования к документации педагогов, регламентируемые основными положениями действующего нормативноправового поля. Особенно детально следует обратить внимание на рабочую программу дисциплин, которая является «настольным» документом для учителя, поскольку именно в программе конкретизируются результаты освоения предмета и фиксируются те средства, приемы и методы, с помощью которых педагог в данных условиях сможет их достичь.

В методическом материале, представленном рабочими программами под редакцией Б.М. Неменского, художественная деятельность в школе представляется как активный процесс, целью которого является формирование художественной культуры обучающихся, развитие художественного мышления, способности к творческой деятельности. Обучающимся необходимо овладевать языком изобразительного искусства, осваивать с помощью собственной активной продуктивной деятельности средства изобразительного искусства (композицию, свойства цвета, линию, пятно и тд.) и изучать содержание произведений искусства посредством художественно-эстетического восприятия [9, с. 3].

В разделе «Общая характеристика учебного предмета» рекомендованы следующие основные виды учебной деятельности: практическая художественно-творческая деятельность, в которой ребенок выступает в роли художника, и деятельность восприятия красоты окружающего мира, произведений искусства, которое «предполагает развитие специальных навыков, чувств, а также овладение образным языком искусства» [9, с. 3], в которой ребенок выступает в роли зрителя.

Обратимся к характеристике видов деятельности обучающихся, на уроках изобразительного искусства, которые представлены в разделе «Тематическое планирование» [10, с. 5-8]. Анализ показывает, что основное внимание уделяется освоению языка изобразительного искусства в процессе практической художественнотворческой деятельности (ребенок в роли художника), тогда как развитие навыков восприятия произведений искусства (ребенок в роли зрителя) находится на периферии учебной художественной деятельности.

Следует отметить, что, если в педагогической теории структура учебной художественной деятельности в шко- 
ле соответствует структуре профессиональной художественной деятельности и представляет собой систему, состоящую из трех звеньев (ребенок-художник, произведение искусства, ребенок-зритель), то в современной педагогической практике все обучающиеся в основном изучают различные материалы и техники изобразительного творчества, а процесс восприятия практически игнорируется. Так, анализ рабочих программ по ИЗО учителей, работающих в разных регионах РФ, показывает, что среди форм учебной деятельности на уроках практически отсутствует восприятие художественного произведения $[19,20]$. Между тем процесс художественного восприятия является очень важным, ведь его конечной целью является формирование и развитие личности обучающегося.

В рамках нашего исследования необходимо более детально рассмотреть процесс художественного восприятия. Так, в работах О.А. Кривцуна подчеркивается факт художественного восприятия как цели, имеющей особую ценность. [14, с. 214]. В работах ряда педагогов художественное восприятие выступает как психический процесс, который взаимосвязан с аспектами психической жизни: мышление, репрезентация, художественноэстетические эмоции. В ходе наблюдения за процессом художественного восприятия специалистами в области нейронауки доказано, что с помощью искусства у зрителя создается художественный образ, который участвует в творческом процессе, воссоздавая в собственном сознании зрителя концепцию художника, т.е., процесс восприятия является активным [13].

Содержание преподавания предметов художественного цикла в школе строится с дифференциацией по возрасту и при обучении детей изобразительному искусству учитываются этапы развития личности. Основным периодом становления личности является подростковый возраст. Рассматривая процесс обучения изобразительному искусству в школе, можно отметить, что в подростковом возрасте упор делается на активное взаимодействие творческой практики и развитие эмоциональной и эстетической отзывчивости. В процессе художественной деятельности в школе обучающийся является субъектом восприятия и объектом влияния. Описывая восприятие произведений искусства подростками, А.В. Бакушинский, В.С. Кузин, 3.Н. Новлянская указывают в качестве основных признаков понимание идеи, темы, сюжета, способность глубоко раскрывать произведение, переживать его под управлением педагога [20, с.74-76]. Художественное восприятие в подростковом возрасте представляет собой сложный и противоречивый процесс, но, развивая у подростка интерес к накопленному в искусстве опыту человечества, можно воспитать высоконравственного, образованного и разностороннего современного человека.
Определяя подростковый возраст как самый трудный и сложный из всех детских возрастов, мы полагаем, что в этом возрасте возникает необходимость в рассмотрении иного подхода к преподаванию «Изобразительного искусства» в школе. Мы считаем, что для формирования самостоятельной, творчески мыслящей личности и лучшего освоения художественных ценностей обучающимися подросткового возраста педагогам при определении структуры урока «Изобразительного искусства» необходимо опираться на процесс восприятия и не выделять практику освоения элементов языка изобразительного искусства.

\section{Зак^ючительная часть}

Таким образом, анализ научной философской, психолого-педагогической литературы позволяет сделать вывод о том, что художественная деятельность, осваиваемая и реализуемая в системе общего образования, - это сложный процесс познания обучающимися отраженной в произведении искусства художественной информации. В нашем исследовании мы опираемся на понятие художественной деятельности М.С. Кагана и определяем художественную деятельность в системе общего образования как совокупность взаимосвязанных элементов, образующих определенную целостность.

Художественная деятельность в школе представляет собой единую систему, состоящую из трех звеньев.

Первое звено - ученик, овладевающий языками искусства. Задачей обучающегося является формирование и развитие способности к пониманию языка искусства.

Второе звено - само произведение искусства разных видов и жанров, являющееся носителем и передатчиком художественной информации. Созданный художественный образ вызывает у человека ассоциации с переживаниями, в результате искусство всесторонне и целостно воздействует на человека.

Третье звено - восприятие искусства в процессе которого ученик (читатель-зритель-слушатель) вступает в диалог с художественным произведением и его автором. В процессе восприятия происходит постоянное соотнесение узнаваемой информации с общим жизненным опытом воспринимающего.

Обучающемуся необходимо обладать определенной системой ценностных ориентаций, необходимой для понимания и глубокого переживания содержания произведения искусства, так как от того какого реальное содержание потенциала личности обучающегося зависит обработка закодированной в произведении искусства художественной информации. Восприятие мы определяем как активную деятельность, в ходе которой извле- 
кается информация, закодированная художником-автором в произведении искусства. Мы определяем процесс восприятия как основное звено художественной деятельности, которому принадлежит ведущая роль в реализации функции искусства «очеловечивать человека».

Изучение особенностей художественной деятельности в системе общего образования позволило сформулировать следующие методические рекомендации в области преподавания дисциплины «Изобразительное искусство»:

- для организации современного урока в школе педагогам необходимо понимание содержания художественной деятельности как системы;

- для усвоения обучающимися программного материала в полном объеме необходимо использование на уроках всех элементов художественной деятельности;

- для наиболее эффективного принятия художественных ценностей обучающимися подросткового возраста в школе необходимо делать акцент на процесс восприятия искусства.
Следуя предложенным выше методическим рекомендациям, педагоги смогут преобразовать учебный процесс таким образом, что обучающиеся освоят все формы учебной деятельности на уроке.

В рамках данной статьи раскрыто содержание понятия «художественная деятельность в школе», рассмотрен понятийный аппарат системы образования и проанализирован практический опыт преподавания дисциплины «Изобразительное искусство». На основании анализа учебно-методической и научной литературы было сформулировано определение художественной деятельности в системе общего образования, представлена ее структура, состоящая из трех компонентов. На уроках изобразительного искусства в школе необходимо развивать навык художественного восприятия обучающихся. Восприятие является важнейшим элементом художественной деятельности, поскольку с помощью процесса восприятия произведений искусства можно формировать и преобразовывать ценности ребенка, являющиеся фундаментом развития личности.

\section{ЛИТЕРАТУРА}

1. Амиржанова, А.Ш. Основные подходы к определению понятия «художественная деятельность» // Омский научный вестник. 2008. №3 (67). С. 172-175.

2. Беседа на тему «Возможности педагогики искусства в системе общего образования»// Научно-методический журнал «Искусство в школе». [Электронный ресурс] URL: art-inschool.ru/ru/beseda-na-temu-vozmozhnosti-pedagogika-iskusstva-v-sisteme-obshchego-obrazovaniya-1 (дата обращения: 18.03.2020).

3. Большаков, В.П., Иконникова, С.Н. Теория культуры: Питер, 2008. - 592 с.

4. Горев, В.В. Художественная деятельность как способ самопознания и развития личности: автореферат дис. ... кандидата психологических наук: 19.00 .01 /Психол. ин-т Рос. акад. образования. М., 2003. - 18 с.

5. Закон «0б образовании в Российской Федерации». М.: Сфера, 2014. - 192 с. 4.

6. Затямина, Т.А. Классическая музыка в формировании мотивационной направленности подростков на продуктивную музыкально-творческую деятельность / Педагогика школы/2015. С.41- 45.

7. Изобразительное искусство. Рабочие программы. Предметная линия учебников под редакцией Б.М. Неменского. 5 - 8 классы : учеб. пособие для общеобразоват. организаций / [Б.М. Неменский, Л.А. Неменская, Н.А. Горяева, А.С. Питерских]. — 4+е изд. — М. : Просвещение, 2015. — 176 с.

8. Изобразительное искусство. Рабочие программы. Предметная линия учебников под редакцией Б.М. Неменского. 1 - 4 классы : пособие для учителей общеобразоват. организаций / [Б.М. Неменский, Л.А. Неменская, Н.А. Горяева и др.]; под ред. Б.М. Неменского. — 5(е изд. — М.: Просвещение, 2015 $-128 \mathrm{c}$.

9. Каган, М.С. Художественная деятельность как информационная система // Системный подход и гуманитарное знание: Избранные статьи. - Л.: Издательство Ленинградского университета, 1991. 384 с. С.208-240.

10. Корнеева, В.А. Формирование приемов художественной деятельности у детей различных возрастов: автореферат дис. ... кандидата психологических наук: 19.00 .07 /Моск. гос. ун-т им. М.В. Ломоносова. - Москва, 2003. - 28 с.

11. Красота и мозг. Биологические аспекты эстетики: Пер. с англ./Под ред. И. Ренчлера, Б. Херцбергер, Д. Эпстайна. М.: Мир, 1995. 335 с.

12. Кривцун, 0.А. Эстетика/ Учебник. М.: Аспект Пресс, 2000. - 434 с.

13. Новиков, А.М., Новиков, Д.А. Методология. - М.: СИН - ТЕГ., 2007 г. -668 с.

14. Пузыни, Т.Г. Педагогические условия формирования авторства подростков в художественной деятельности : автореферат дис. ... кандидата педагогических наук : 13.00.01 / Ярослав. гос. пед. ун-т им. К. Д. Ушинского. - Ярославль, 2003. - 23 с.

15. Рабочая программа по изобразительному искусству для 7 класса Республики Адыгея. [Электронный ресурс] URL: https://nsportal.ru/shkola/izobrazitelnoeiskusstvo/library/2015/11/05/rabochaya-programma-po-izo-7-klass-fgos (дата обращения: 20.03.2020).

16. Рабочая программа по предмету «Изобразительное искусство» 8 класс MO «Бичурский район» Республики Бурятия. [Электронный ресурс] URL: https:// infourok.ru/rabochaya-programma-po-izo-fgos-8-klass-4076380.html (дата обращения: 20.03.2020).

17. Развитие художественного восприятия ребенка (для обучающихся по дополнительной квалификации «Преподаватель»)»: [учебное пособие]/ Федераль- 
ное агентство по образованию ГОУ ВПо «Уральский государственный университет им. А.М. Горького» Центр педагогического образования. Екатеринбург, 2008. -203 c.

18. Стратегия развития воспитания в Российской Федерации на период до 2025 года. [Электронный ресурс] URL: http://static.government.ru/media/files/f5Z8H 9tgUK5Y9qtJ0tEFnyHIBitwN4gB.pdf (дата обращения: 20.03.2020).

19. Таньчева, И.В. Педагогическое сопровождение становления субъектной позиции подростка в художественной деятельности: дис. ... канд. пед. наук. Саратов, 2013. 223 с.

20. Федеральный государственный образовательный стандарт основного общего образования/ Министерство образования и науки Российской Федерации. М.: Просвещение, 2010.

\section{( Денисенко Олеся Анатольевна (mak-olesya@yandex.ru).}

Журнал «Современная наука: актуальные проблемы теории и практики»

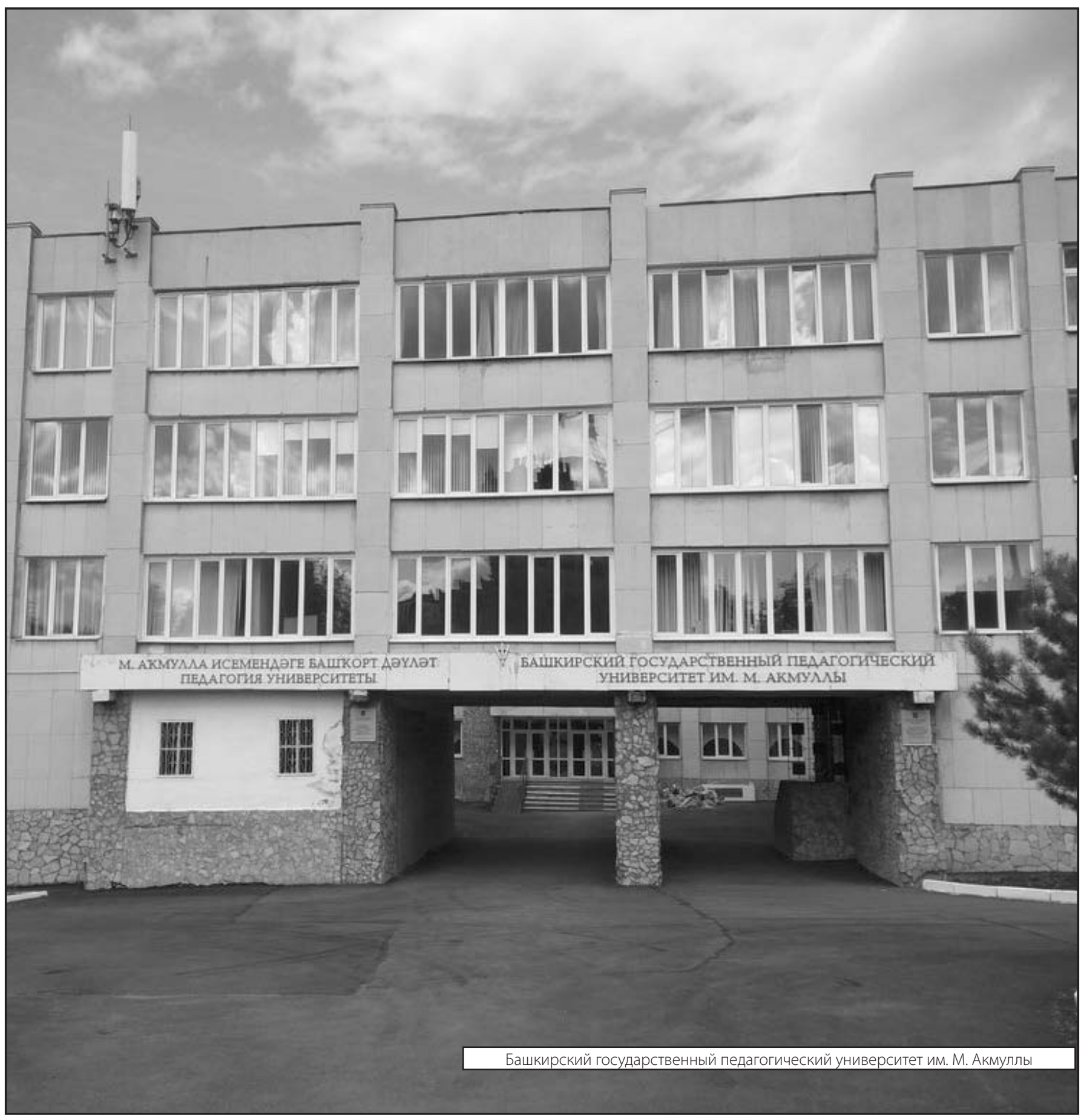

